\title{
Surgical treatment of lumbosacral tuberculosis by one-stage debridement and anterior instrumentation with allograft through an extraperitoneal anterior approach
}

\author{
Jian-Hua Li ${ }^{1}$, Ze-Hua Zhang ${ }^{1 *}$, Tao Shi ${ }^{1}$, Fei Dai ${ }^{1}$, Qiang Zhou' ${ }^{1}$, Fei Luo ${ }^{1}$, Tian-Yong Hou' ${ }^{1}$, Qing-Yi He ${ }^{1}$, \\ Mo-Yuan Deng ${ }^{2}$ and Jian-Zhong $\mathrm{Xu}^{1^{*}}$
}

\begin{abstract}
Background: This study was aimed to investigate the clinical outcome of lumbosacral tuberculosis treatment by one-stage radical debridement with bone allograft reconstruction and anterior instrumentation via a retroperitoneal approach.

Methods: We retrospectively analyzed a series of 43 patients with lumbosacral tuberculosis in whom the lumbosacral junction was exposed via an anterior midline retroperitoneal approach. After radical debridement, two parallel tricortical iliac crest bone allografts were placed to reconstruct the anterior column, and then anterior fixation was performed.
\end{abstract}

Results: The mean follow-up period was 34 months (range, 24-91 months), during which no obvious loss of correction was observed. No case experienced recurrence, tuberculous peritonitis, erectile dysfunction, or retrograde ejaculation.

Conclusions: The midline retroperitoneal approach provides direct and safe access to lesions of lumbosacral tuberculosis. Two parallel structural iliac crest allografts and anterior instrumentation effectively stabilize the lumbosacral junction.

Keywords: Anterior approach, Tuberculosis of lumbosacral junction, Internal fixation

\section{Background}

Lumbosacral tuberculosis is a rare condition, representing only $2 \%-3 \%$ of all cases of spinal tuberculosis [1]. Surgical stabilization of the spinopelvic region in patients with lumbosacral tuberculosis remains a challenge clinically due to the complex anatomy and biomechanics of the affected region. Most of the previously reported procedures adopt the single- or two-stage combined anteroposterior approaches. Despite good clinical outcomes, the surgical trauma involved in these procedures is severe and the cost is relatively high [2]. In addition, the anterior surgical approach allows for direct and complete removal of the lesion, relief of spinal cord

\footnotetext{
*Correspondence: zhangzehuatmmu@qq.com; xujianzhong2014@163.com 'Department of Orthopaedics, Southwest Hospital, Third Military Medical University, Gaotanyan Street 29, Shapingba District, Chongqing 400038, China

Full list of author information is available at the end of the article
}

compression, and restoration/recovery of spinal stability. It has been shown that one-stage decompression, fusion, and internal fixation can achieve excellent outcomes in the treatment of thoracolumbar tuberculosis [3-5]. From July 2001 to December 2011, we treated 43 patients with tuberculosis of the lumbosacral junction with a onestage operation involving lumbar interbody fusion with allografts via the retroperitoneal approach.

\section{Methods}

Clinical data

In this retrospective study, we analyzed outcomes for all 43 consecutive patients treated for lumbosacral tuberculosis at our hospital from July 2001 to December 2011. Patients included 20 males and 23 females with a median age of 40 years (range, 20-69 years). The disease duration prior to treatment ranged from 1 month to 6 years (mean, 15.47 months). Among these patients, 27 
Table 1 Patient demographics, operative information, and disease characteristics

\begin{tabular}{|c|c|c|c|c|c|c|c|}
\hline Patient & Age (years) & Gender & $\begin{array}{l}\text { Operation } \\
\text { time (minutes) }\end{array}$ & Blood loss $(\mathrm{mL})$ & Level & $\begin{array}{l}\text { Duration of symptoms } \\
\text { (months) }\end{array}$ & $\begin{array}{l}\text { Length of follow-up } \\
\text { (months) }\end{array}$ \\
\hline 1 & 25 & $M$ & 145 & 200 & L5-S1 & 18 & 27 \\
\hline 2 & 23 & M & 150 & 200 & L5-S1 & 12 & 27 \\
\hline 3 & 53 & $\mathrm{~F}$ & 150 & 200 & L5-S1 & 6 & 33 \\
\hline 4 & 20 & M & 170 & 150 & L5-S1 & 36 & 27 \\
\hline 5 & 50 & M & 170 & 150 & L5-S1 & 12 & 27 \\
\hline 6 & 36 & $\mathrm{~F}$ & 285 & 500 & L5-S1 & 12 & 91 \\
\hline 7 & 25 & M & 210 & 200 & L5-S1 & 12 & 28 \\
\hline 8 & 33 & $\mathrm{~F}$ & 175 & 200 & L5-S1 & 12 & 30 \\
\hline 9 & 46 & $\mathrm{~F}$ & 160 & 250 & L5-S1 & 7 & 32 \\
\hline 10 & 61 & $\mathrm{~F}$ & 525 & 600 & L5-S1 & 36 & 73 \\
\hline 11 & 59 & M & 645 & 800 & L5-S1 & 4 & 51 \\
\hline 12 & 26 & $\mathrm{~F}$ & 755 & 800 & L5-S1 & 24 & 50 \\
\hline 13 & 41 & M & 180 & 350 & L5-S1 & 12 & 33 \\
\hline 14 & 30 & $\mathrm{~F}$ & 765 & 800 & L5-S1 & 60 & 60 \\
\hline 15 & 65 & M & 540 & 400 & L5-S1 & 1 & 27 \\
\hline 16 & 47 & $M$ & 348 & 400 & L5-S1 & 3 & 30 \\
\hline 17 & 69 & $M$ & 80 & 200 & L5-S1 & 5 & 33 \\
\hline 18 & 54 & $M$ & 172 & 200 & L5-S1 & 3 & 43 \\
\hline 19 & 40 & $\mathrm{~F}$ & 167 & 200 & L5-S1 & 6 & 33 \\
\hline 20 & 57 & $M$ & 190 & 300 & L5-S1 & 5 & 33 \\
\hline 21 & 35 & $\mathrm{~F}$ & 125 & 250 & L5-S1 & 6 & 39 \\
\hline 22 & 37 & $\mathrm{~F}$ & 160 & 600 & L1-S1 & 60 & 27 \\
\hline 23 & 25 & $M$ & 500 & 1600 & L2-S1 & 2 & 27 \\
\hline 24 & 40 & $\mathrm{~F}$ & 135 & 200 & L5-S1 & 7 & 35 \\
\hline 25 & 60 & $\mathrm{~F}$ & 210 & 500 & L5-S2 & 6 & 29 \\
\hline 26 & 53 & $M$ & 100 & 150 & L5-S1 & 12 & 39 \\
\hline 27 & 24 & $M$ & 177 & 200 & L3-S1 & 24 & 28 \\
\hline 28 & 23 & M & 132 & 200 & L5-S1 & 24 & 32 \\
\hline 29 & 47 & $\mathrm{~F}$ & 151 & 200 & L5-S1 & 72 & 27 \\
\hline 30 & 44 & $M$ & 188 & 400 & L4-S2 & 12 & 27 \\
\hline 31 & 68 & $\mathrm{~F}$ & 148 & 400 & L5-S2 & 2 & 33 \\
\hline 32 & 31 & $\mathrm{~F}$ & 159 & 800 & L4-S1 & 10 & 51 \\
\hline 33 & 21 & $M$ & 170 & 800 & L5-S1 & 12 & 27 \\
\hline 34 & 39 & $\mathrm{~F}$ & 127 & 300 & L5-S1 & 12 & 27 \\
\hline 35 & 44 & $M$ & 147 & 200 & L5-S1 & 12 & 31 \\
\hline 36 & 24 & $M$ & 156 & 200 & L5-S1 & 4 & 29 \\
\hline 37 & 25 & $M$ & 225 & 300 & L5-S1 & 9 & 28 \\
\hline 38 & 44 & M & 112 & 200 & L5-S1 & 8 & 27 \\
\hline 39 & 36 & $M$ & 241 & 600 & L5-S1 & 4 & 26 \\
\hline 40 & 46 & $\mathrm{~F}$ & 208 & 500 & L5-S1 & 24 & 25 \\
\hline 41 & 33 & $F$ & 110 & 200 & L5-S1 & 3 & 25 \\
\hline
\end{tabular}


Table 1 Patient demographics, operative information, and disease characteristics (Continued)

\begin{tabular}{lllllllll}
\hline 42 & 36 & $F$ & 140 & 300 & L5-S1 & 24 & & 43 \\
43 & 34 & $F$ & 130 & 300 & L5-S1 & 30 & & 24 \\
Mean \pm SD & $40.21 \pm 13.75$ & - & $231.00 \pm 170.75$ & $383.72 \pm 280.46$ & & & $15.47 \pm 16.18$ & $34.74 \pm 13.45$ \\
\hline
\end{tabular}

$S D$ standard deviation, $M$ male, $F$ female.

had complained severe or moderate back pain; 21 reported radiation pain in the lower limb; and 16 had muscle strength loss, pain, and hypoesthesia in the lower limbs. Plain radiography, computed tomography (CT), and/or magnetic resonance imaging (MRI) were performed on all the patients before surgery and showed that the lesions were all located in the L5-S1 segments. Paravertebral abscesses were observed in 40 patients, and vertebral damage was clearly observed in all patients. Intervertebral space was found to be narrower. Overall, 26 cases presented with presacral abscess, 9 cases with fistula from L5 paravertebral abscesses, 16 cases with pulmonary tuberculosis, and 7 cases with sacroiliac joint tuberculosis. Before surgery, the average lumbosacral angle was $13.30^{\circ}\left(\right.$ range, $5^{\circ}-20^{\circ}$ ) $[6,7]$, and the average blood sedimentation rate was $45.67 \mathrm{~mm} / \mathrm{h}$ (range, $25-76 \mathrm{~mm} / \mathrm{h}$ ). Antituberculosis chemotherapy was administered for at least 2 weeks (Tables 1 and 2).

\section{Surgical procedure}

The patient was placed in the supine position with the feet higher than the head. Epidural anesthesia was induced, and then a median incision was made through the skin along the symphysis pubis to the umbilicus. The skin and subcutaneous tissue were dissected off the anterior rectus sheath. The parietal peritoneum was bluntly dissected using the hand and gauze, and the peritoneum and its contents were slightly pushed inward to expose the anterior lumbosacral spine (Figure 1A). Then the sacral promontory was located, and the abdominal aorta, inferior vena cava, and its bifurcations were identified. The median sacral artery and vein were ligated, and then a horizontal $\mathrm{H}$ shaped longitudinal incision was made along the midline with the sacral promontory as the center to reveal the lesions, during which the hypogastric plexus and the ureters were carefully protected. The prevertebral fascia and the abscess were cut open to drain the pus (Figure 1B, C). The lesion was isolated with wet gauze to prevent contamination of the surrounding tissues and spread of Mycobacterium tuberculosis. A curette and rongeur were used to clear the pus, caseous necrotic tissue, granulation tissue, necrotic bone, and intervertebral disc (Figure 1D). The wound was irrigated with hydrogen peroxide and then physiological saline repeatedly until the effluent was clear. The intervertebral space was expanded appropriately to measure the extent of the bone defect. Two tricortical allograft iliac bones were trimmed to the proper size and then tightly inserted into the L5-S1 bone groove (Figure 1E).
Two self-locking titanium anterior lumbosacral vertebrae plates (PACH; General Corp., Germany) of suitable length were selected and anteriorly fixed at L5-S1 (Figure 1F). Hemostasis was achieved, and the wound was thoroughly irrigated. Then $1 \mathrm{~g}$ of streptomycin and $0.6 \mathrm{~g}$ of isoniazid were placed around the implant [8]. Then, the normal cancellous bone collected during the procedure outlined in Figure 1D and demineralized bone matrix (DBM) were mixed and implanted into the gap around the steel plates on both sides of the grafted bone. For patients with sacroiliac joint tuberculosis, in which the abscess was in front of the joint, the surgical techniques can be similar to the procedure described, and the surgical procedure may differ in other conditions. The incision was sutured layer by layer. The stitches were removed 10 days after surgery after the wounds had healed well. A thoracolumbar orthosis was maintained for 6 months after surgery, combined with antituberculous chemotherapy for 12 months.

\section{Surgical evaluation}

During the surgery, the abdominal aorta, inferior vena cava, and its bifurcations were identified as the first key points, and the hypogastric plexus and ureters were carefully protected during the process of clearing the pus. The pus must be cleared completely, and the nerves, blood vessels, and other organs not be hurt. The two tricortical allograft iliac bones must be tightly inserted into the L5S1 bone groove, and the PACH should be impartial. We could check them and could also see the effect by X-ray. After the surgery, it was necessary to pay attention to the basic state of the patient, checking the ESR, CRP, etc. Xray and $\mathrm{CT}$ were repeated at 3 days after the surgery. If the patient had no serious hemorrhoids or defecatory, urinary, or erectile dysfunction and the device was not displaced, we considered the surgery to be successful. All patients were followed up systematically, and outcomes were analyzed. The Bridwell criteria were used to estimate the degree of bone union in the patients.

\section{Results}

The mean operative time was 231.00 min (range, 80$765 \mathrm{~min}$ ), and the mean blood loss volume was $383.72 \mathrm{~mL}$ (range, 150-1600 mL). No injuries to the large blood vessels, nerves, or ureters occurred in these patients, and none of the 20 male patients experienced erectile dysfunction during the follow-up period. None of the patients developed wound infection or fistula. Two patients suffered 
Table 2 Radiological and clinical outcomes

\begin{tabular}{|c|c|c|c|c|c|c|c|c|c|c|}
\hline \multirow[t]{2}{*}{ Patient } & \multicolumn{3}{|c|}{ Lumbosacral angle $\left({ }^{\circ}\right)$} & \multicolumn{3}{|c|}{ VAS score } & \multicolumn{3}{|c|}{ ESR $(\mathrm{mm} / \mathrm{h})$} & \multirow{2}{*}{$\begin{array}{l}\text { Bone fusion } \\
\text { (months) }\end{array}$} \\
\hline & Preop & Postop $^{a}$ & Final & Preop & Postop $^{b}$ & Final & Preop & Postop $^{a}$ & Final & \\
\hline 1 & 7 & 16 & 14 & 7 & 1 & 0 & 47 & 10 & 12 & 9 \\
\hline 2 & 10 & 15 & 14 & 7 & 1 & 0 & 60 & 26 & 7 & 8 \\
\hline 3 & 15 & 22 & 20 & 8 & 2 & 0 & 58 & 26 & 11 & 10 \\
\hline 4 & 5 & 17 & 15 & 5 & 1 & 1 & 39 & 20 & 7 & 8 \\
\hline 5 & 20 & 29 & 28 & 9 & 1 & 1 & 46 & 13 & 9 & 8 \\
\hline 6 & 13 & 24 & 22 & 7 & 2 & 1 & 54 & 11 & 9 & 9 \\
\hline 7 & 16 & 28 & 24 & 7 & 1 & 1 & 31 & 5 & 6 & 9 \\
\hline 8 & 20 & 30 & 28 & 8 & 2 & 0 & 29 & 5 & 8 & 9 \\
\hline 9 & 11 & 13 & 17 & 7 & 1 & 0 & 31 & 5 & 8 & 8 \\
\hline 10 & 16 & 25 & 24 & 9 & 2 & 1 & 25 & 6 & 9 & 8 \\
\hline 11 & 11 & 13 & 12 & 7 & 1 & 0 & 25 & 6 & 11 & 9 \\
\hline 12 & 15 & 22 & 21 & 8 & 2 & 0 & 29 & 14 & 11 & 9 \\
\hline 13 & 20 & 27 & 26 & 8 & 2 & 1 & 46 & 7 & 11 & 9 \\
\hline 14 & 17 & 26 & 25 & 8 & 2 & 0 & 57 & 11 & 8 & 8 \\
\hline 15 & 8 & 18 & 14 & 6 & 1 & 0 & 33 & 6 & 9 & 9 \\
\hline 16 & 11 & 16 & 15 & 7 & 1 & 0 & 59 & 18 & 7 & 8 \\
\hline 17 & 12 & 23 & 21 & 7 & 2 & 1 & 76 & 11 & 7 & 9 \\
\hline 18 & 12 & 23 & 22 & 7 & 2 & 0 & 39 & 17 & 14 & 10 \\
\hline 19 & 9 & 17 & 17 & 6 & 1 & 0 & 35 & 11 & 9 & 9 \\
\hline 20 & 20 & 30 & 28 & 8 & 2 & 0 & 62 & 12 & 8 & 8 \\
\hline 21 & 16 & 28 & 23 & 7 & 1 & 1 & 66 & 14 & 11 & 8 \\
\hline 22 & 12 & 23 & 23 & 7 & 2 & 1 & 30 & 13 & 11 & 9 \\
\hline 23 & 11 & 13 & 16 & 7 & 1 & 0 & 42 & 8 & 9 & 8 \\
\hline 24 & 16 & 25 & 25 & 9 & 2 & 1 & 47 & 7 & 7 & 11 \\
\hline 25 & 13 & 24 & 22 & 7 & 2 & 1 & 50 & 16 & 11 & 9 \\
\hline 26 & 11 & 13 & 14 & 7 & 1 & 0 & 29 & 13 & 12 & 9 \\
\hline 27 & 11 & 13 & 14 & 7 & 1 & 0 & 39 & 12 & 8 & 9 \\
\hline 28 & 6 & 17 & 15 & 7 & 2 & 1 & 46 & 7 & 9 & 9 \\
\hline 29 & 9 & 19 & 17 & 6 & 1 & 1 & 62 & 12 & 8 & 9 \\
\hline 30 & 12 & 21 & 21 & 7 & 2 & 0 & 45 & 14 & 9 & 8 \\
\hline 31 & 20 & 27 & 25 & 9 & 1 & 1 & 53 & 15 & 7 & 8 \\
\hline 32 & 18 & 26 & 24 & 9 & 1 & 1 & 61 & 10 & 12 & 8 \\
\hline 33 & 17 & 25 & 23 & 9 & 1 & 1 & 37 & 9 & 10 & 8 \\
\hline 34 & 15 & 25 & 24 & 8 & 2 & 0 & 64 & 16 & 11 & 8 \\
\hline 35 & 10 & 15 & 13 & 6 & 1 & 1 & 74 & 14 & 11 & 9 \\
\hline 36 & 9 & 15 & 13 & 6 & 1 & 1 & 48 & 9 & 9 & 8 \\
\hline 37 & 13 & 24 & 21 & 7 & 2 & 0 & 32 & 12 & 7 & 8 \\
\hline 38 & 14 & 27 & 24 & 7 & 2 & 1 & 36 & 14 & 11 & 8 \\
\hline 39 & 19 & 25 & 25 & 8 & 2 & 0 & 55 & 8 & 9 & 9 \\
\hline 40 & 14 & 25 & 24 & 8 & 2 & 0 & 55 & 4 & 8 & 9 \\
\hline 41 & 11 & 16 & 15 & 7 & 1 & 0 & 31 & 7 & 8 & 10 \\
\hline
\end{tabular}


Table 2 Radiological and clinical outcomes (Continued)

\begin{tabular}{|c|c|c|c|c|c|c|c|c|c|c|}
\hline 42 & 13 & 25 & 23 & 7 & 2 & 1 & 34 & 9 & 7 & 10 \\
\hline 43 & 14 & 24 & 20 & 8 & 2 & 0 & 47 & 9 & 10 & 10 \\
\hline Mean \pm SD & $13.3 \pm 3.96$ & $21.6 \pm 5.33^{*}$ & $20.26 \pm 4.78^{*}$ & $7.35 \pm 0.95$ & $1.51 \pm 0.51^{*}$ & $0.47 \pm 0.50^{*}$ & $45.67 \pm 13.56$ & $11.44 \pm 5.04^{*}$ & $9.21 \pm 1.83^{*}$ & $8.74 \pm 0.76$ \\
\hline
\end{tabular}

ESR erythrocyte sedimentation rate, preop preoperative, postop postoperative, $S D$ standard deviation, VAS visual analogue scale.

*Indicates a statistically significant difference between the mean postop or final value and the mean preoperative value (all $P<0.01$ ).

${ }^{\text {ap }}$ ostoperative follow-up at 3 months.

${ }^{\text {b}}$ Postoperative follow-up at 6 months.

abdominal distention, and two patients suffered urinary retention after surgery. The 43 patients were followed up for a mean period of 34.74 months (range, 24-91 months), and no patients experienced recurrence of the disease during follow-up. It should be mentioned that the recurrence rate is $2 \%-5 \%$ in the long term (5-10 years) [9-11].

Partial absorption of the edge of the bone was observed in two patients. According to the Bridwell criteria [12], at the last follow-up, bone union of grade I (Figures 2,3,4, and 5) occurred in 41 cases, with the healing time ranging from 8 to 11 months, and bone union of grade II occurred in 2 cases 11 months after the surgery. In addition, the erythrocyte sedimentation rate (ESR) was found to be normal, and back pain with radiation in the lower limbs had disappeared. The mean lumbosacral angle was $21.60^{\circ}$ (range, $13^{\circ}-30^{\circ}$ ) after the operation and $20.26^{\circ}$ (range, $13^{\circ}-28^{\circ}$ ) at the last follow-up (Tables 1 and 2).

\section{Discussion}

L5-S1 is a spinal segment located between the lumbar lordosis and sacral kyphosis. As these vertebrae bear the majority of body weight, the stability of this segment is critical. In addition, the upper surface of S1 vertebra slants forward, and therefore, there is a high risk of L5 spondylolisthesis. The L5-S1 zygopophysis and intervertebral disc are the main structures responsible for resisting L5 spondylolisthesis. In patients with L5-S1 vertebral tuberculosis, the damaged intervertebral discs and vertebrae, as well as the decreased lumbosacral angle, may dislocate the L5-S1 joint, leading to joint capsule laxity. Therefore, the L5-S1 intervertebral disc must be removed during debridement of tuberculosis lesions. However, without the intervertebral disc, the shear stress between L5 and S1 can cause accelerated degradation of the zygopophysis, leading to back pain. Thus, an important goal of treatment is to recover the

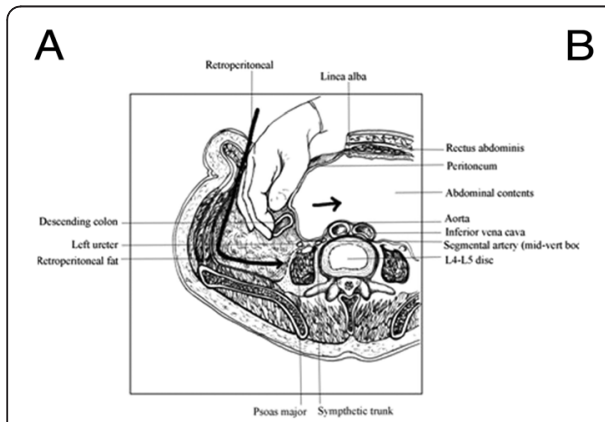

B
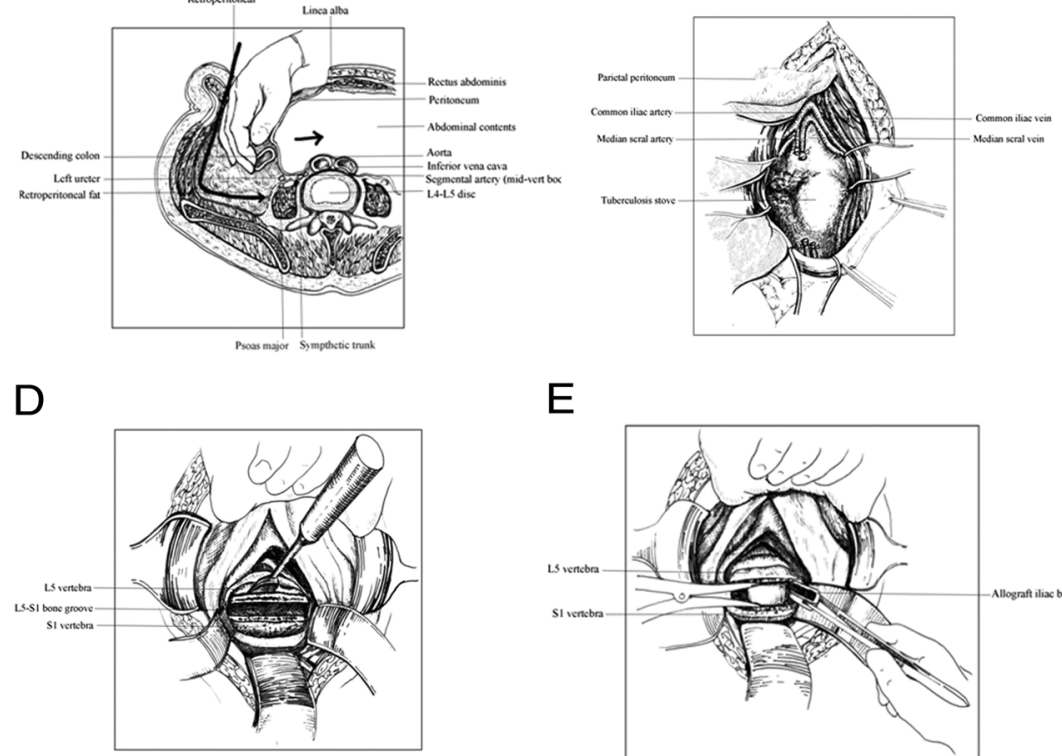

E

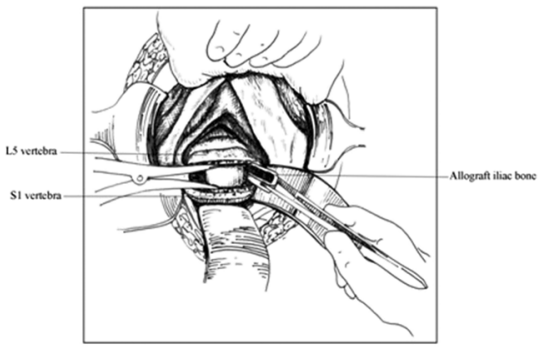

C

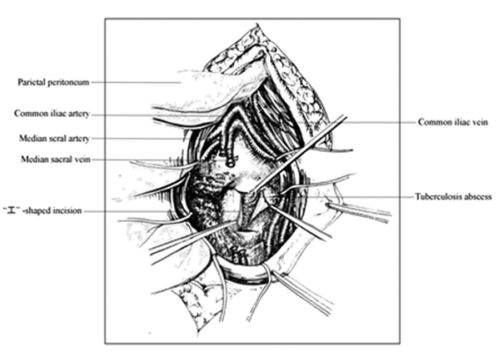

$\mathrm{F}$

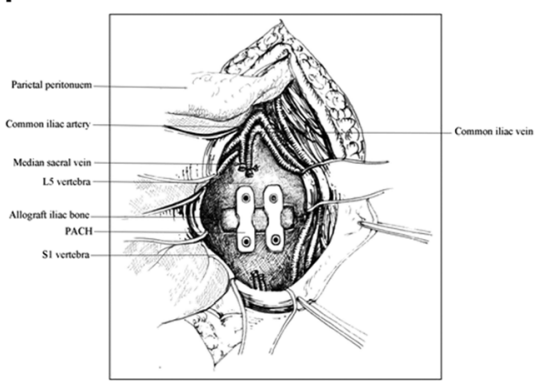

Figure 1 The surgical procedure used in the study. (A) Exposure of the anterior lumbosacral spine. (B) Ligation of the median sacral artery and vein. (C) An "H"-shaped longitudinal incision and removal of pus. (D) The pus, caseous necrotic tissue, granulation tissue, necrotic bone, and intervertebral disc are removed. (E) Two tricortical allograft iliac bones were trimmed to the proper size and then tightly inserted into the L5-S1 bone groove. (F) Two self-locking titanium anterior lumbosacral vertebrae plates (PACH; General Corp., Germany) of suitable length were selected and anteriorly fixed at L5-S1. 


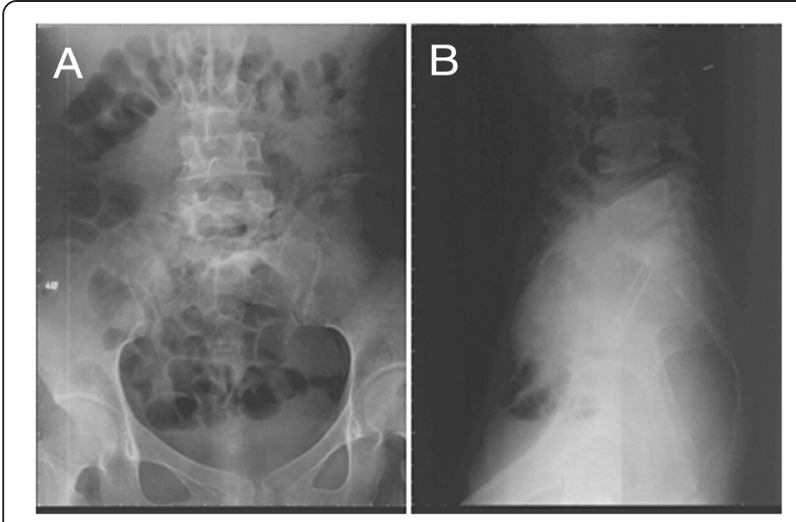

Figure 2 X-ray showing L5-S1 vertebral damage with narrowed intervertebral space and lumbosacral angle of $16^{\circ}$. (A) Anteroposterior view and (B) lateral view.

height of vertebrae and prevent local shear and axial stresses via bone graft fusion. However, the intervertebral bone graft may slip forward during rotation or extension movement of the lumbar spine, and it is essential to use internal fixation for early reconstruction and maintenance of the vertebrae [13-16]. A posterior approach to fixation of the lumbosacral segments has been performed at a safe distance from the tuberculosis lesion but is time-consuming and quite invasive [2]. Here, we tested the effectiveness and safety of one-stage radical debridement with bone allograft reconstruction and anterior instrumentation via a retroperitoneal approach to treatment patients with lumbosacral tuberculosis.

The anterior approach to the lower lumbar spine includes the extraperitoneal or intraperitoneal approaches. The common iliac artery and vein are located anteriorlaterally to the L5 vertebra. Although the extraperitoneal approach can clearly expose the lumbosacral segments, this approach can lead to injury of the blood vessels and ureters. On the contrary, the intraperitoneal approach to the L5-S1 anterior interbody fusion has the following advantages: (1) incision through the linea alba can avoid

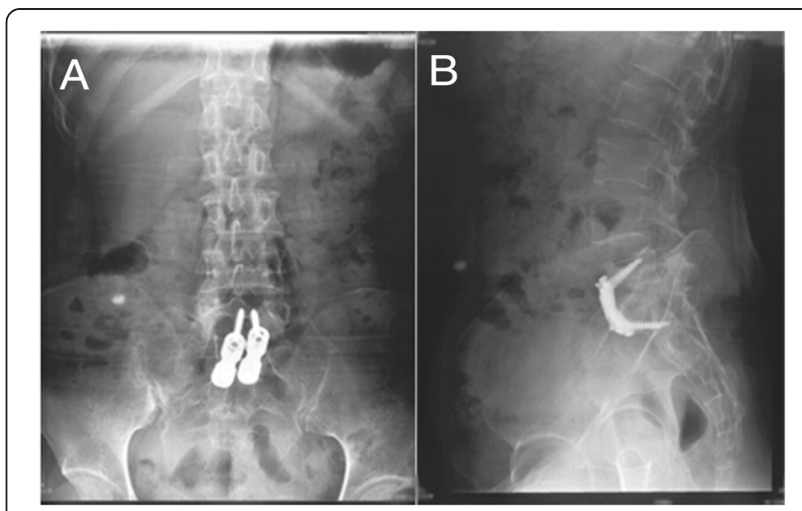

Figure 4 At 1 year postoperatively, the lumbosacral angle was $23^{\circ}$. (A) Anteroposterior view and (B) lateral view.

muscular damage; (2) lesions located anteriorly and bilaterally to the sacrum can be fully exposed and debrided, which can facilitate the anterior internal fixation; and (3) a direct view can minimize surgical damage to blood vessels, nerves, and ureters $[17,18]$. In our patients, only mild complications occurred postoperatively, such as abdominal distention and urinary retention, which resolved spontaneously without special treatment. No severe complications, such as tuberculous peritonitis, intestinal obstruction, erectile dysfunction, and retrograde ejaculation, were observed during the long-term follow-up.

Most patients with spinal tuberculosis will have good outcomes after conservative treatments. However, the surgical approach applied in this study may be considered in patients with the following conditions: large presacral abscess or sequestrum, severely damaged vertebrae that require reconstruction for stability, history of previous multiple surgeries conducted via the transperitoneal approach with local tissue and intestine adhesion, and female.

Through 100 years of development, allograft bone transplantation has become a mature technology with minimal risks of immune rejection and infection [19-21]. The American Association of Tissue Banks (AATB) has
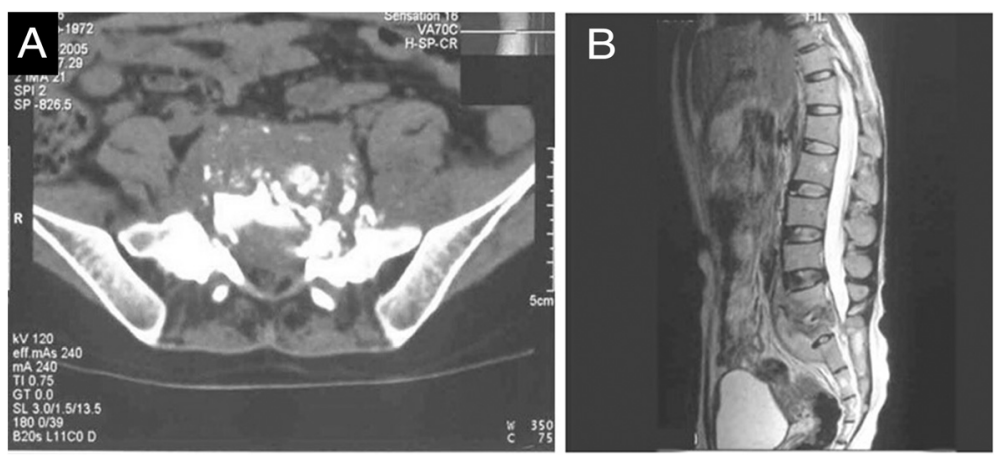

Figure 3 CT and MR images showing bone union of grade I. (A) CT image showing S1 bone destruction, presacral cold abscess, and sequestrum. (B) MRI showing L5-S1 vertebral signal change, narrowed intervertebral space, and presacral cold abscess. 


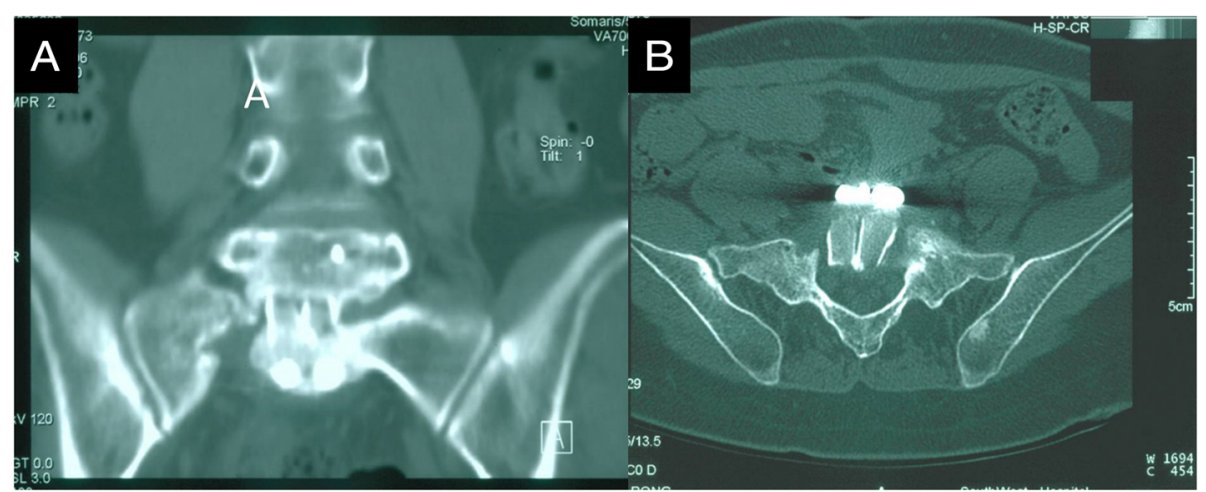

Figure 5 One year after operation, CT images showed that the trabecular bone was reconstructed well without photic zone, grade I bony fusion. (A) Anteroposterior view and (B) axial view.

proposed and continually updates guidelines for the acquisition, processing, sterilization, and preservation of allogeneic bones, and most bone banks worldwide adopt these recommendations [22]. Allograft bone transplantation has been used for lumbar interbody fusion in the treatment of spinal tuberculosis and achieved good outcomes. Most of these allografts are obtained from freshly frozen femur or humerus rings [23-29]. In our patients, freeze-dried iliac allografts were used for lumbar interbody fusion. We found that the allogeneic iliac blocks can easily be trimmed to the desired shapes and sizes. The tricortical iliac crest bone grafts also have good biomechanical performance and can withstand strong compression forces. The cancellous bones at both ends of the grafts immediately contact the cortical bones of the upper and lower vertebrae, facilitating the replacement by host bone tissues. In this study, we inserted two allogeneic iliac crest bone blocks in a parallel manner into the L5-S1 intervertebral space and achieved good spine stability.

Postoperative radiographs and CT images at 3-6 months showed partial absorption of the upper or lower edge of the allografts in two patients. This may have been associated with the replacement of the allogeneic bones and slight loosening of the internal fixation. The two patients achieved grade II bone union at postoperative 9 and 11 months, respectively. The time to bone union in these patients was obviously longer than that achieved with the use of autografts. However, the allografts were satisfactory in terms of deformity correction and stability restoration. In addition, allogeneic iliac crest bone grafting has advantages over autografts including shorter operation time and avoidance of donor site morbidity.

\section{Conclusions}

In conclusion, the midline retroperitoneal approach provides direct and safe access to lesions of lumbosacral tuberculosis. Moreover, interbody fusion with iliac crest allografts and anterior instrumentation can effectively restore the lumbosacral junction stability.

\section{Abbreviations}

CT: Computed tomography; MRI: Magnetic resonance imaging; DBM: Demineralized bone matrix.

\section{Competing interests}

The authors declare that they have no competing interests.

\section{Authors' contributions}

$\mathrm{JHL}$ carried out the therapy and follow-up for all patients, participated in the data collection and analysis, and drafted the manuscript. TS, FD, QZ, FL, TYH, QYH, and MYD carried out the therapy and follow-up for all patients. ZHZ and JZX conceived of the study, participated in the design of the study, and helped to draft the manuscript. All authors read and approved the final manuscript.

\section{Acknowledgements}

The authors are grateful to the graphic artists of the Department of Pathology, Southwest Hospital for help with drawing Figure 1. This study was approved by the Southwest Hospital Ethics Committee and was supported by the Clinical Innovation Fund of Third Military Medical University (Grant No. SWH2011015).

\section{Author details}

'Department of Orthopaedics, Southwest Hospital, Third Military Medical University, Gaotanyan Street 29, Shapingba District, Chongqing 400038, China. ${ }^{2}$ National \& Regional United Engineering Laboratory of Tissue Engineering, Southwest Hospital, Third Military Medical University, Chongqing, China.

Received: 6 February 2015 Accepted: 14 March 2015

Published online: 10 May 2015

\section{References}

1. Rajasekaran S, Shanmugasundaram TK, Prabhakar R, Dheenadhayalan J, Shetty AP, Shetty DK. Tuberculous lesions of the lumbosacral region. A 15-year follow-up of patients treated by ambulant chemotherapy. Spine (Phila Pa 1976). 1998;23:1163-7.

2. Bezer M, Kucukdurmaz F, Aydin N, Kocaoglu B, Guven O. Tuberculous spondylitis of the lumbosacral region: long-term follow-up of patients treated by chemotherapy, transpedicular drainage, posterior instrumentation, and fusion. J Spinal Disord Tech. 2005;18:425-9.

3. Zhao J, Lian XF, Hou TS, Ma H, Chen ZM. Anterior debridement and bone grafting of spinal tuberculosis with one-stage instrumentation anteriorly or posteriorly. Int Orthop. 2007;31:859-63. 
4. Dai LY, Jiang LS, Wang W, Cui YM. Single-stage anterior autogenous bone grafting and instrumentation in the surgical management of spinal tuberculosis. Spine (Phila Pa 1976). 2005;30:2342-9.

5. Benli IT, Acaroglu E, Akalin S, Kis M, Duman E, Un A. Anterior radical debridement and anterior instrumentation in tuberculosis spondylitis. Eur Spine J. 2003;12:224-34.

6. Zhang XF, Wang Y, Zhang BX. The treatment of degenerative lumbar spondylolisthesis with intervertebral threaded fusion cage (TFC). Orthop J Chin. 2002;10:856-8.

7. Liu YX, Jin H, Li JS. The measurement method and significance of lumbosacral angle. The Journal of Traditional Chinese Orthopedics and Traumatology. 2004;16:601-2.

8. Xu JZ, Zhang ZH, Zhou Q. The outcome of allograft and instrumentation in the treatment of lumbosacral junction tuberculosis. Chinese Journal of Spine and Spinal Cord. 2006;16:897-900.

9. Wang $\mathrm{R}$, Kong $\mathrm{XH}$, Chen QY, Mei ZX, Tong XY. To explore the relation between erythrocyte sedimentation rate and postoperative recurrence of spinal tuberculosis. Zhongguo Gu Shang. 2008;21:291-3.

10. Tuli SM. Tuberculosis of the spine: a historical review. Clin Orthop Relat Res. 2007:460:29-38.

11. Ling T, Liu L, Yang X, Qiang Z, Hu X, An Y. Revision surgery for spinal tuberculosis with secondary deformity after treatment with debridement, instrumentation, and fusion. Eur Spine J 2014; 1-9.

12. Bridwell KH, Lenke LG, McEnery KW, Baldus C, Blanke K. Anterior fresh frozen structural allografts in the thoracic and lumbar spine. Do they work if combined with posterior fusion and instrumentation in adult patients with kyphosis or anterior column defects? Spine (Phila Pa 1976). 1995;20:1410-8.

13. Luk KDK. Spinal tuberculosis. Current Opinion in Orthopaedics. 2000;11:196-201.

14. Kim DJ, Yun YH, Moon SH, Riew KD. Posterior instrumentation using compressive laminar hooks and anterior interbody arthrodesis for the treatment of tuberculosis of the lower lumbar spine. Spine (Phila Pa 1976). 2004;29:E275-9.

15. Rajasekaran S. The problem of deformity in spinal tuberculosis. Clin Orthop Relat Res. 2002;398:85-92.

16. Rezai AR, Lee M, Cooper PR, Errico TJ, Koslow M. Modern management of spinal tuberculosis. Neurosurgery. 1995;36:87-97. discussion -8.

17. Holt RT, Majd ME, Vadhva M, Castro FP. The efficacy of anterior spine exposure by an orthopedic surgeon. J Spinal Disord Tech. 2003;16:477-86.

18. Cohn EB, Ignatoff JM, Keeler TC, Shapiro DE, Blum MD. Exposure of the anterior spine: technique and experience with 66 patients. J Urol. 2000;164:416-8

19. Uchiyama K, Ujihira M, Mabuchi K, Takahira N, Komiya K, Itoman M. Development of heating method by microwave for sterilization of bone allografts. J Orthop Sci. 2005;10:77-83.

20. Arjmand B, Aghayan HR, Larijani B, Sahebjam M, Ghaderi F, Goodarzi P. The effect of gamma irradiation on the osteoinductivity of demineralized human bone allograft. Acta Med Iran. 2014;52:215-9.

21. Liu JW, Chao LH, Su LH, Wang JW, Wang CJ. Experience with a bone bank operation and allograft bone infection in recipients at a medical centre in southern Taiwan. J Hosp Infect. 2002;50:293-7.

22. AATB. Standards for tissue banking. 13th ed. 2014.

23. Govender $\mathrm{S}$. The outcome of allografts and anterior instrumentation in spinal tuberculosis. Clin Orthop Relat Res. 2002;398:60-6.

24. Molinari RW, Bridwell KH, Klepps SJ, Baldus C. Minimum 5-year follow-up of anterior column structural allografts in the thoracic and lumbar spine. Spine (Phila Pa 1976). 1999;24:967-72.

25. Lan X, Liu XM, Ge BF. Debridement and bone grafting with internal fixation via anterior approach for treatment of cervicothoracic tuberculosis Int Surg. 2011;96:358-62.

26. Cavusoglu H, Kaya RA, Turkmenoglu ON, Tuncer C, Colak I, Aydin Y. A long-term follow-up study of anterior tibial allografting and instrumentation in the management of thoracolumbar tuberculous spondylitis. J Neurosurg Spine. 2008;8:30-8.

27. Wang X, Luo C, Wu P. Single-stage transpedicular decompression, debridement, posterior instrumentation and fusion for thoracic tuberculosis with kyphosis and spinal cord compression in aged. Spine J 2013.

28. Wang XT, Zhou CL, Xi CY, Sun CL, Yan JL. Surgical treatment of cervicothoracic junction spinal tuberculosis via combined anterior and posterior approaches in children. Chin Med J (Engl). 2012;125:1443-7.

29. Govender S, Parbhoo AH. Support of the anterior column with allografts in tuberculosis of the spine. J Bone Joint Surg Br. 1999;81:106-9.

\section{Submit your next manuscript to BioMed Central and take full advantage of:}

- Convenient online submission

- Thorough peer review

- No space constraints or color figure charges

- Immediate publication on acceptance

- Inclusion in PubMed, CAS, Scopus and Google Scholar

- Research which is freely available for redistribution

Submit your manuscript at www.biomedcentral.com/submit 